\begin{tabular}{|c|l|}
\hline Title & Development of ultra fine grain binderless cBN tool for precision cutting of ferrous materials \\
\hline Author(s) & $\begin{array}{l}\text { Fujisaki, Kazuhiro; Y okota, Hideo; Furushiro, Naomichi; Y amagata, Y utaka; Taniguchi, Takashi; Himeno, Ryutaro; } \\
\text { Makinouchi, A kitake; Higuchi, Toshiro }\end{array}$ \\
\hline Citation & $\begin{array}{l}\text { Journal of Materials Processing Technology, 209(15-16), 5646-5652 } \\
\text { https:/doi.org/10.1016/.jmatprotec.2009.05.023 }\end{array}$ \\
\hline Issue Date & 2009-08-01 \\
\hline Doc URL & http://hdl.handle.net/2115/39399 \\
\hline Type & article (author version) \\
\hline File Information & JMPT 209-15-16_p5646-5652.pdf \\
\hline
\end{tabular}

Instructions for use 


\title{
Development of Ultra-Fine-Grain Binderless cBN Tool for Precision Cutting of Ferrous Materials
}

\author{
Kazuhiro Fujisaki ${ }^{1,2}$, Hideo Yokota ${ }^{2,3,1}$, Naomichi Furushiro ${ }^{4}$, Yutaka Yamagata ${ }^{2}$, \\ Takashi Taniguchi ${ }^{5}$, Ryutaro Himeno ${ }^{3}$, Akitake Makinouchi ${ }^{2}$, and Toshiro Higuchi ${ }^{6,3}$ \\ *1 Division of Human Mechanical Systems and Design, Graduate School of Engineering, \\ Hokkaido University, N13 W8, Kita-ku, Sapporo 060-8628, JAPAN \\ *2 VCAD System Research Program, RIKEN, 2-1, Hirosawa, Wako, Saitama 351-0198, JAPAN \\ *3 Living Matter Simulation Research Group, Advanced Computational Sciences Department, \\ Advanced Science Institute, RIKEN, 2-1, Hirosawa, Wako, Saitama 351-0198, JAPAN \\ ${ }^{*}$ Department of Mechanical Engineering, Faculty of Engineering Science, Kansai University, \\ 3-3-35, Yamate-cho, Suita, Osaka 564-8680, JAPAN \\ ${ }^{*}$ National Institute for Materials Sciences, 1-1 Namiki, Tsukuba, Ibaraki 305-0044, JAPAN \\ ${ }^{*}$ Department of Precision Machinery Engineering, University of Tokyo, 7-3-1 Hongo, \\ Bunkyo-ku, Tokyo 113-8656, JAPAN
}




\section{Corresponding author:}

Kazuhiro FUJISAKI

Division of Human Mechanical Systems and Design, Graduate School of Engineering,

Hokkaido University, N13 W8, Kita-ku, Sapporo, 060-8628, JAPAN

TEL \& FAX: +81-11-706-6396, E-mail: fujiwax@eng.hokudai.ac.jp

\section{Manuscript type:}

"Research papers" 


\section{Abstract}

A new cutting tool was developed from ultra-fine-grain $(<100 \mathrm{~nm})$, binderless cubic boron nitride $(\mathrm{cBN})$ material fabricated by transforming hexagonal boron nitride to $\mathrm{cBN}$ by means of sintering under an ultra-high pressure of $10 \mathrm{GPa}$ at $1800{ }^{\circ} \mathrm{C}$. The cutting edges of the newly developed $\mathrm{cBN}$ tool can be made as sharp as those of single-crystal diamond tools. In this experiment, $\mathrm{cBN}$ and single crystal diamond tools of the same shape were compared by precision cutting tests using stainless steel specimens and steel specimens coated with an electroless Ni-P layer. The surface roughness $\left(R_{z}\right)$ of specimen surfaces cut with the $\mathrm{cBN}$ tool by means of planing was approximately $100 \mathrm{~nm}$ for both the Ni-P-coated steel and stainless steel specimens. Though similar $R_{z}$ values were obtained for Ni-P layers cut by the $\mathrm{cBN}$ and diamond tools, an $R_{z}$ value exceeding 2000 nm was obtained for stainless steel cut by the diamond tool. High-precision surfaces with $R_{z}$ values of 50 - $100 \mathrm{~nm}$ were obtained for stainless steel specimens cut with the cBN tool under high-speed milling $(942 \mathrm{~m} / \mathrm{min})$ conditions. These results indicate that the newly developed cBN tool is useful for the ultra-precision or precision cutting of ferrous materials.

Key words: high-precision machining, cubic boron nitride, single- crystal diamond tool, mirror-like surface, ferrous material 


\section{Introduction}

Precision cutting of ferrous material is important for most manufacturing processes, including precision mould fabrication. Diamond tools are usually used for the precision machining of certain types of metals and plastic materials. However, diamond tools are not suitable for the precision cutting of ferrous materials because these tools incur marked wear at the places where the cutting edge contacts the ferrous material. The reasons for such wear have been explained not only in terms of mechanical damages but also in terms of thermal effects and chemical reactions. Shimada et al. (2004) investigated the interaction of diamond and ferrous materials under high temperature and explained the mechanism of wear. Paul et al. (1996) investigated the relationship between the wear of diamond tools during cutting and the existence of unpaired electrons in the materials being cut. They investigated whether diamond tools could be applied to certain elements in the turning process. Tool wear is a serious problem in realizing mirror-like surfaces in precision cutting, and some techniques have been proposed for decreasing wear caused by chemical reactions at the contact region between the tool and material. Stabilization layer coating the surface of tools helps to prevent direct contact between the diamond tool and work materials, but such coatings reduce tool original durability. Brinksmeier et al. (2006) showed that the wear on 
diamond tools could be reduced by thermo-chemically treating steel with a nitriding process, thus preventing chemical reaction with the diamond tool. Shamoto and Moriwaki (1994) proposed a precision cutting method using an ultrasonic elliptical vibration tool, which was used for precision cutting of hardened steel materials under the turning process (Shamoto and Moriwaki (1999)). This ultrasonic cutting method reduces contact time and friction between the tool and the work material (Klocke et al. (2004)). Although this system performs high precision cutting that is suitable for processing ferrous materials, the system requires a vibration unit with an oscillator; it must be designed with total mass control, including the cutting edge, in order to control vibration; and the cutting speed must be set at a low range that is limited by the vibration period. Additionally, Moriwaki et al. (2004) developed an elliptical vibration milling system that can reduce the cutting force and tool wear less than conventional milling without vibration.

Cubic boron nitride $(\mathrm{cBN})$ is a promising alternative material to diamond for cutting tools. cBN has the second-highest hardness after diamond and good characteristics in terms of heat and chemical resistance. cBN materials are already used in tools for milling and grinding ferrous materials in manufacturing. Generally, cBN materials are fabricated by sintering with binder metals. $\mathrm{cBN}$ are also used to coat only a part of the 
cutting edge of silicon or cemented carbide tool (Bewilogua et al., 2004). In sintered cBN materials containing binder metals, tool wear is caused mainly by the low strength of the binder metal (Luo et al., 1999). Recently, sintered "binderless" cBN materials, which contain no weak areas since they contain no binder metals, have been developed and are already being put to practical use in the usual finishing processes of milling or turning. Furthermore, fine-grain, binderless polycrystalline cBN materials and single-crystal $\mathrm{cBN}$ materials are produced in sintering processes under high pressure $(5$ - $8 \mathrm{GPa}$ ) and at temperatures exceeding $1500^{\circ} \mathrm{C}$ (Taniguchi et al., 1999; Taniguchi and Yamaoka, 2001). The ability of cutting tools to produce mirror-like surfaces under precision cutting conditions depends on how sharp the tools' cutting edges are. Polishing techniques can be used to create sharp edges for single-crystal materials, such as single-crystal diamond materials and ultra-fine-grain polycrystalline materials. Nishiguchi and Masuda (1988) developed single-crystal cBN tools and reported their performance in the precision cutting of steel materials. Although steel surfaces can be finished to a mirror-like face by turning with single-crystal $\mathrm{cBN}$ tools, tool wear at cutting edges tends to progress relatively quickly during this process. Neo et al. (2003) reported that commercial binderless and pure $\mathrm{cBN}$ tools can be used for precision cutting by sharpening their blade edges. 
The mechanical properties of sintered $\mathrm{cBN}$ materials depend on the size of the $\mathrm{cBN}$ particles that compose the sintering body. Chou and Evans (1997) showed that the hardness and transverse rupture strength in sintered $\mathrm{cBN}$ tools containing binder metals are greater in small-grain cBN than they are in large-grain cBN. In precision cutting, the particle size has an important role in determining the surface roughness of the machined material, because a rough blade surface caused by particle loss or tool edge abrasion is directly transcribed onto the working surface. These surface features remaining on the mould determine the accuracy of products; such accuracy is especially important in moulding of precision optical components. In this study, we developed a new cutting tool composed of ultra-fine-grain $(<100 \mathrm{~nm})$, binderless $\mathrm{cBN}$ that was fabricated by a sintering process under ultra-high pressure, and successfully sharpened the cutting edges of this newly developed $\mathrm{cBN}$ tool so that the edges were as sharp as those of single-crystal diamond tools. The performance of the $\mathrm{cBN}$ tools was evaluated from precision cutting tests for stainless steel, for which we evaluated the resulting surface roughness and surface images, including cutting path patterns within the working materials. 
2. Development of the $\mathrm{cBN}$ tool

Polycrystalline, binderless $\mathrm{cBN}$ is made under high temperature and high pressure (Taniguchi et al., 1999, 2004). In this study, ultra-fine-grain $(<100 \mathrm{~nm})$, binderless cBN was fabricated by transforming hexagonal boron nitride $(\mathrm{hBN})$ to $\mathrm{cBN}$ by means of sintering a cBN circular plate of $7 \mathrm{~mm}$ diameter and $0.7 \mathrm{~mm}$ thickness under an ultra-high pressure of $10 \mathrm{GPa}$ at $\sim 1800{ }^{\circ} \mathrm{C}$. Fig. 1 shows a microscopic image of the sintered cBN particles observed by field-emission scanning electron microscopy (FE-SEM; JEOL JSM-6330F) at a fracture site cross-section within the cBN material. It can be seen from the figure that the $\mathrm{cBN}$ material is composed of many fine-grain $\mathrm{cBN}$ particles. Maximum size of the particles was confirmed as less than $100 \mathrm{~nm}$. The sintered cBN plate was divided into eight equal wedges (Fig. 2a) by a circular saw with a diamond-resin blade of $0.15 \mathrm{~mm}$ thickness and $>1 \mathrm{~mm}$ blade depth. The cBN abraded the blade markedly during cutting; only two wedges could be cut per blade before the blade had to be replaced. Each $\mathrm{cBN}$ wedge was then shaped into a cutting tool; Fig. $2 \mathrm{~b}$ shows a representative photo of such a $\mathrm{cBN}$ tool. Each wedge was bonded by brazing on a sintered hard alloy, which can be placed on a shank for planing or on a turning wheel for milling. The cutting edge of each wedge was formed into a round shape and polished to be as sharp as possible, producing a round edge of $0.5 \mathrm{~mm}$ radius, a rake 
angle of $0^{\circ}$, and clearance of $7^{\circ}$ as shown in Fig. 2b. These dimensions are comparable to those of a commercially available single-crystal diamond tool. Fig. 3 shows micrographs of the rake faces of the blade edges of a) the cBN tool and b) the single-crystal diamond tool. The cutting edges of both tools were accurately formed to a round shape with a $500 \pm 2 \mu \mathrm{m}$ radius. The higher resolution image of cutting edge of the cBN tool which area was marked in Fig. 3 a was observed by FE-SEM (Fig. 3 c)). The cutting edges of the newly developed $\mathrm{cBN}$ tools could be made as sharp as those of the single-crystal diamond tool with smooth curve on submicron scale.

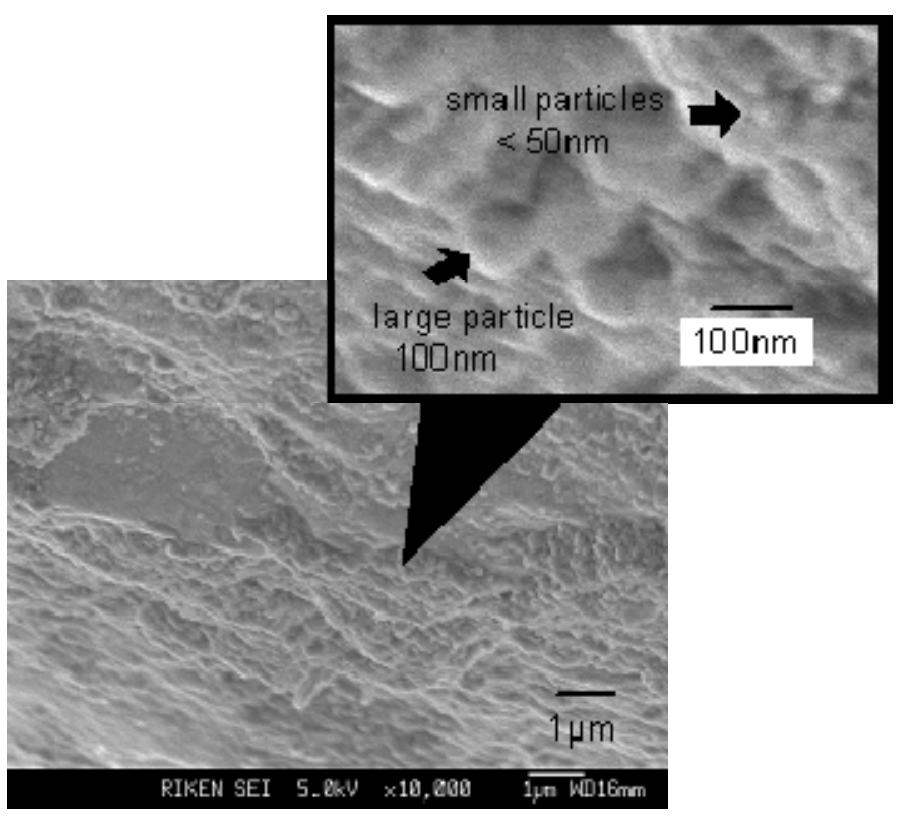

Fig. 1 FE-SEM image of the cross-section of sintered ultra-fine-grain cBN at 10000 -fold magnification. 


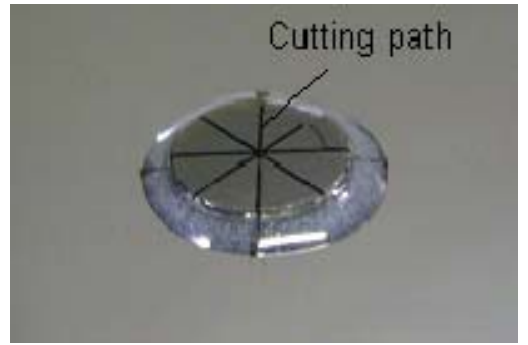

a) cEN sinered body $\infty$

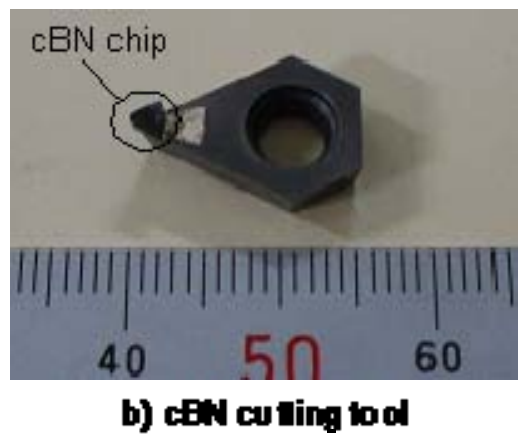

Fig. 2 Photographs of a) the sintered cBN plate, with eight wedge divisions marked, and

b) a cBN tool formed with same configuration as that of a commercially available

diamond tool. 


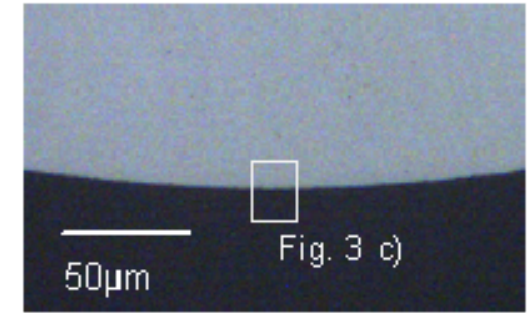

a) Unira-fing-grain cefN tool

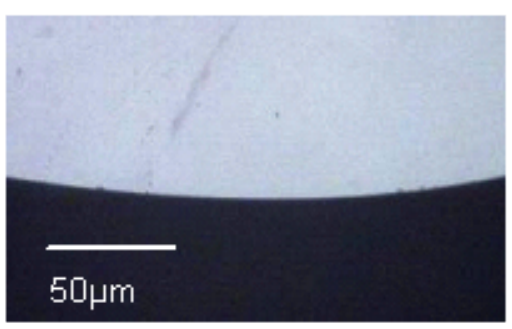

b) Single crystal diam ond lood

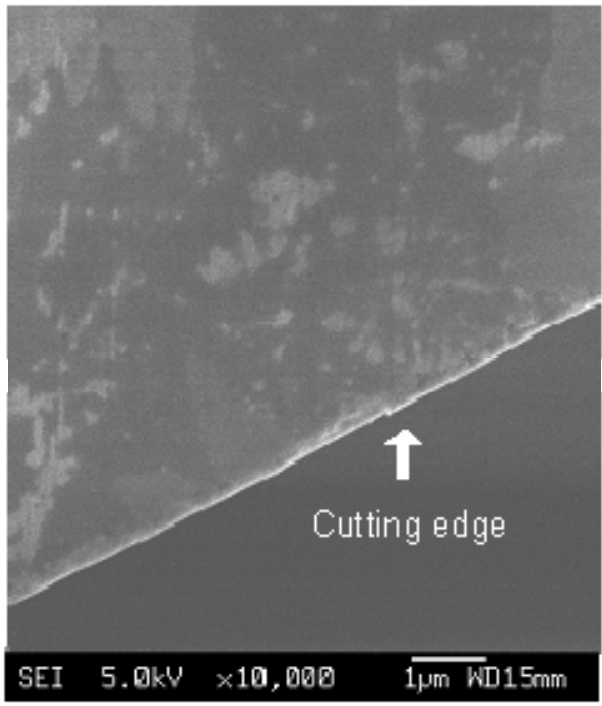

c) SEA impge of calling edge of cEN

Fig. 3 Microscopic images of rake faces of the blade edges of a) the cBN tool and b) a commercially available single-crystal diamond tool. c) The higher resolution image of cutting edge of the cBN tool which area was marked in Fig. 3 a) was observed by

\section{FE-SEM.}

\section{Experimental procedure}

\subsection{Specimens}

The newly developed cBN tools were compared with commercial single-crystal diamond tools of the same shape by means of precision cutting tests and by comparing the surface roughness of specimens cut by the tools. A $15 \mathrm{~mm}$ diameter, $30 \mathrm{~mm}$ high cylinder of heat-treated stainless steel (SUS420J2, HRC 50) was used in these tests. A 
second type of specimen was created by deposition of a $100 \mu \mathrm{m}$ thick layer of electroless Ni-P on pieces of steel. The surface of this electroless Ni-P layer can be made mirror-like by precision cutting with diamond tools. Both specimens were fixed on an aluminium alloy plate $(\mathrm{A} 7075) 40 \times 60 \times 10 \mathrm{~mm}$ in size and placed on a cast-steel surface on the XY table of the precision cutting machine for mirror surface processing. In addition, to confirm the versatility of the $\mathrm{cBN}$ tool, the same machining process was carried out on aluminium cast alloy (ADC12) specimens and medium carbon steel (S50C) specimens.

\subsection{Precision cutting}

The precision cutting tests were performed with a high-precision milling machine (Toshiba Machine, UVM-350(J)) equipped with a three-dimensional internal structure microscope (Riken Micro Slicer System - 003) (Furushiro et al., 2008) as shown in Fig. 4a. The Z-axis of the machine has a large surface plate to attach a milling spindle, which can turn rapidly at a maximum speed of 30000 revolutions per minute by air bearing, and to attach an optical microscope unit. The $\mathrm{X}, \mathrm{Y}$, and $\mathrm{Z}$ tables feature a high-resolution feedback scale $(0.1 \mu \mathrm{m}$ for each axis), and precision positioning was 
performed by a numerical control (NC) system (TOSNUC888) in the milling machine. Two types of machining process, planing (Fig. 4 b) and fly-cutting (Fig. 4 c), were performed by high-speed milling with a single tool. Tools of the same shape were used in each process. Table 1 shows the cutting conditions. For tools with round edges, the tool nose radius and feed determine the surface roughness of the workpieces. The theoretical values of surface roughness $\left(R_{z}\right)$ and maximum peak-to-valley heights on processed surfaces at various feed rates can be calculated as follows:

$$
R_{Z}=r-\sqrt{r^{2}-\left(\frac{f}{2}\right)^{2}}
$$

where $r$ is the nose radius of the tool edge and $f$ is the feed. 


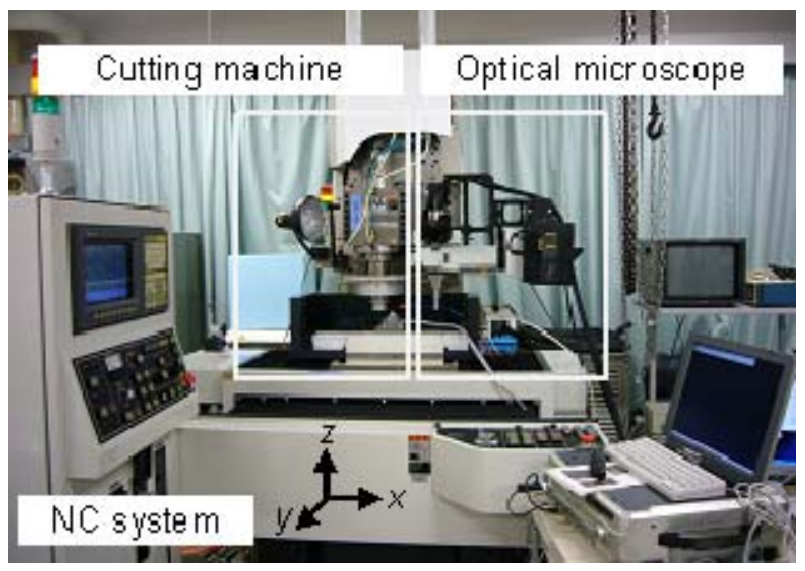

a) Pixen mioro sFear sysiom - 000

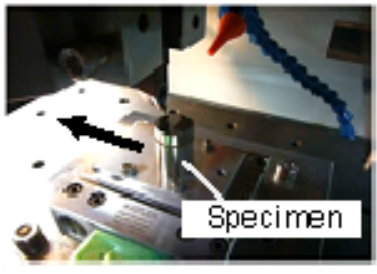

b) Planing

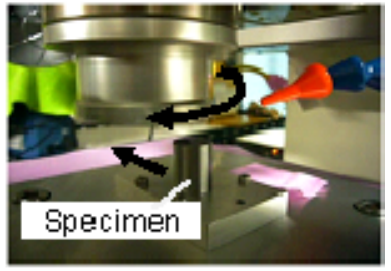

c) Fhyoling

Fig. 4 a) The precision cutting apparatus, which features a high-precision milling

machine and optical microscope. Both b) planing and c) fly-cutting were performed with the milling machine. 
Table 1 Cutting conditions for precision machining

\begin{tabular}{cll}
\hline \multirow{2}{*}{ Tool geometry } & Rake angle & $0^{\circ}$ \\
& Clearance & $7^{\circ}$ \\
& Nose radius & $0.5 \mathrm{~mm}$ \\
\hline \multirow{2}{*}{ Planing } & Cutting speed & $2 \mu \mathrm{m} / \mathrm{min}$ \\
& Feed: $\mathrm{f}$ & $10 \mu \mathrm{m}$ \\
& Cutting depth: $\mathrm{a}_{\mathrm{p}}$ & $5 \mu \mathrm{m}$ \\
& Cutting fluid & Air \\
\hline \multirow{5}{*}{ Fly-cutting } & Cutting speed & $942 \mathrm{~m} / \mathrm{min}$ \\
& Feed: $\mathrm{f}$ & $2 \mu \mathrm{m}, 5 \mu \mathrm{m}$ \\
& Cutting depth: $\mathrm{a}_{\mathrm{p}}$ & $2 \mu \mathrm{m}, 5 \mu \mathrm{m}$ \\
& Cutting fluid & Air \\
\hline
\end{tabular}

In this experiment, surface roughness measurements and microscopic images of specimen surfaces were used for the evaluation of precision cutting performance of the cBN tool. $R_{z}$ (ISO: the mean value of the maximum peak-valley heights) and $R_{a}$ (ISO: the arithmetic mean of the absolute values) value were measured across the cutting path with a non-contact surface profilometer (ZYGO New View 5032). In this measurement, the value of $R_{z}$ was determined as the distance of peak-to-valley height for an area of $144 \times 108 \mu \mathrm{m}$ measured by this profilometer. The $R_{a}$ value was determined from all scanning lines with a length of $144 \mu \mathrm{m}$, across the cutting paths, in this measured area. Microscopic images were obtained by an optical microscope with a long focus lens 
(MITUTOYO M Plan APo SL $\times 50$ ). The resolution of these images was high enough to observe cutting paths of several micrometres, which was equal to the feed rate set in this experiment. When the scratch patterns are detected on the images, the tool edge gets damages and inadequate cutting were occurred and then surface roughness becomes worse.

4. Results

\subsection{Planing}

Planing tests were performed at a cutting speed of $2 \mathrm{~m} / \mathrm{min}$, a feed (f) of $10 \mu \mathrm{m}$, and a cutting depth $\left(a_{\mathrm{p}}\right)$ of $5 \mu \mathrm{m}$ under dry conditions with air blown on each tool and specimen during cutting. The feed effect of the round edge tool on the specimen surface was small because the theoretical value of $R_{z}$ for this condition was calculated from Eq. (1) to be $25 \mathrm{~nm}$. Fig. 5 a and b show surface images of stainless steel and Ni-P-coated steel specimens that were precision-cut with the diamond and cBN tools. Table 2 shows the $R_{z}$ values of these surfaces measured from a $144 \times 108 \mu \mathrm{m}$ area of each specimen. The results for electroless Ni-P-coated steel cut with the diamond tool and with the cBN tool were essentially the same. Likewise, the $R_{z}$ values for the Ni-P-coated steel 
specimens were also similar for both tools: $R_{\mathrm{Z}}$ was $85 \mathrm{~nm}$ for the specimen cut with the diamond tool and $92 \mathrm{~nm}$ for that cut with the $\mathrm{cBN}$ tool. Both surface images were very smooth, without any visible scratches or rubbed patterns. These results show that the cBN tool had sharp blades and maintained this sharpness with minimal tool wear during the electroless Ni-P cutting.

Table 2 Surface roughness $\left(R_{z}\right)$ of specimens for planing at a cutting speed of $2 \mathrm{~m} / \mathrm{min}, \mathrm{f}$ $=10 \mu \mathrm{m}$, and $\mathrm{a}_{\mathrm{p}}=5 \mu \mathrm{m}$, measured for a $144 \times 108 \mu \mathrm{m}$ area by a non-contact surface profilometer

\begin{tabular}{cccc}
\hline Specimen & Tool & $R_{z}$ & $R_{a}$ \\
\hline \multirow{2}{*}{ Electroless Ni-P } & Diamond & 85 & 17 \\
& $\mathrm{cBN}$ & 92 & 16 \\
\hline \multirow{2}{*}{ SUS420J2 } & Diamond & 2006 & 228 \\
& $\mathrm{cBN}$ & 116 & 20 \\
\hline
\end{tabular}

The results for stainless steel cutting differed remarkably between the two tools (Fig. $5 \mathrm{c}$ and $\mathrm{d})$. The surface of the specimen cut with the diamond tool was covered with scars, and the $R_{z}$ value exceeded $2000 \mathrm{~nm}$. After cutting, the diamond tool was also confirmed to have a large crack at the cutting edge. The wear region of the diamond tool 
was too large to attain a mirror-like surface even under precision cutting conditions. In contrast, the $R_{\mathrm{z}}$ value for stainless steel cut with the $\mathrm{cBN}$ tool was $116 \mathrm{~nm}$. Although a regular cutting path could be seen on the surface image of this specimen, the surface roughness across the path did not differ substantially from the machining results for the electroless Ni-P cutting.
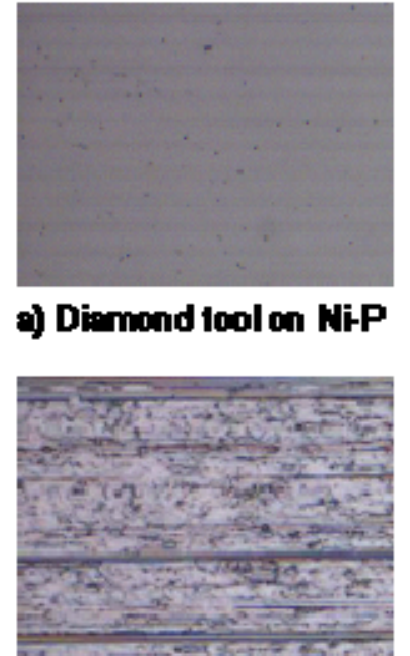

c) Diamond iool on Susarav2

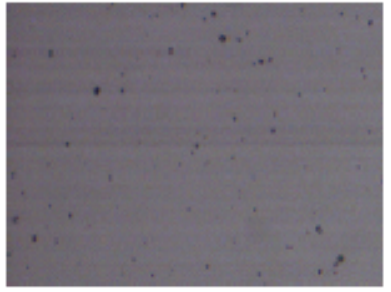

b) CEN 10ol on NiP

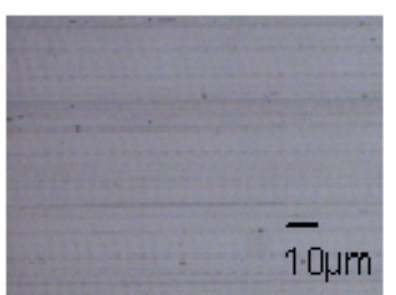

d) cBN lool an SUSERan2

Fig. 5 Microscopic images of the surfaces of each specimen cut by the dry planing

process: a) diamond tool on Ni-P, b) cBN tool on Ni-P, c) diamond tool on SUS420J2, and d) $c B N$ tool on SUS420J2: cutting speed $=2 \mathrm{~m} / \mathrm{min}, \mathrm{f}=10 \mu \mathrm{m}$, and $\mathrm{a}_{\mathrm{p}}=5 \mu \mathrm{m}$ under dry conditions. 


\subsection{High-speed milling}

Initial high-speed milling trials were conducted by machining stainless steel with the cBN tool at a cutting speed of $942 \mathrm{~m} / \mathrm{min}, \mathrm{f}=5 \mu \mathrm{m}$, and $\mathrm{a}_{\mathrm{p}}=5 \mu \mathrm{m}$ under dry conditions with air blowing. The theoretical value of $R_{z}$ was $6 \mathrm{~nm}$. Under these conditions, many sparks were observed during high-speed milling as shown in Fig. 6. Although the surface appearance worsened while the sparks were generated, the $R_{z}$ value was $\sim 100$ nm. To determine the optimal conditions for precision cutting, the feed and cutting depth were decreased until no sparks were generated. Fig. 7 shows the surface of the stainless steel machined by the $\mathrm{cBN}$ tool at a cutting speed of $942 \mathrm{~m} / \mathrm{min}, \mathrm{f}=2 \mu \mathrm{m}$, and $\mathrm{a}_{\mathrm{p}}=2 \mu \mathrm{m}$ under dry conditions with air blowing. The theoretical value of $R_{z}$ was negligible $(1 \mathrm{~nm})$. There were no scars on the surface and hardly any wear at the tool edge. The $R_{z}$ value was $77 \mathrm{~nm}$ as shown in Fig. 8. In some scanning lines with $144 \mu \mathrm{m}$ region, $R_{z}$ was less than $50 \mathrm{~nm}$. These results indicate that the newly developed cBN tool is useful for ultra-precision or precision cutting of ferrous materials even under high-speed cutting and dry conditions. 


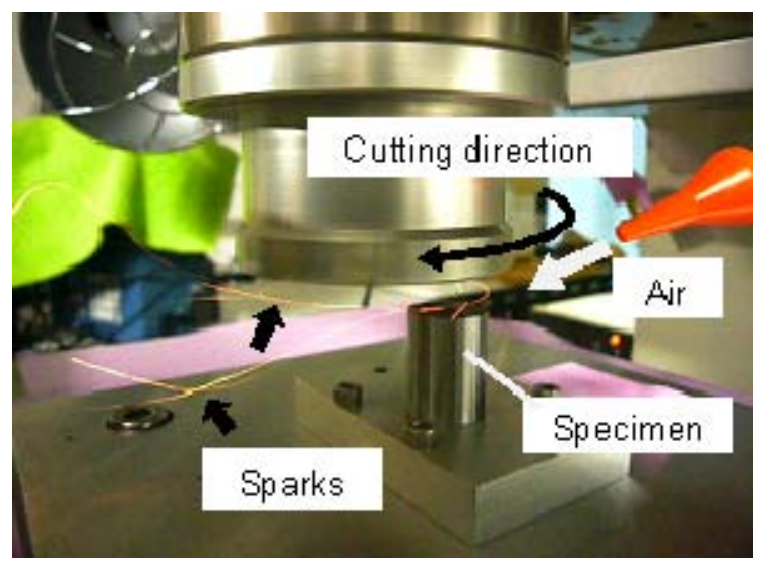

Fig. 6 Photograph of sparks generated when stainless steel was fly-cut with the cBN tool under unsuitable conditions: cutting speed $=942 \mathrm{~m} / \mathrm{min}, \mathrm{f}=5 \mu \mathrm{m}$, and $\mathrm{a}_{\mathrm{p}}=5 \mu \mathrm{m}$ under dry conditions.

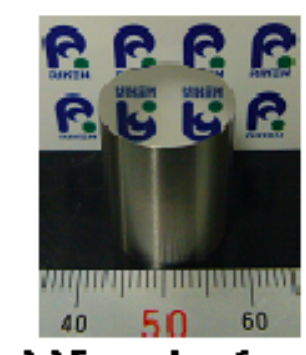

\section{a) Wrored sufface b) micnoscopic imags}

Fig. 7 Surface of a stainless steel specimen fly-cut with the cBN tool under suitable conditions, i.e., without spark generation: cutting speed $=942 \mathrm{~m} / \mathrm{min}, \mathrm{f}=2 \mu \mathrm{m}$, and $\mathrm{a}_{\mathrm{p}}=$ $2 \mu \mathrm{m}$ under dry conditions. 


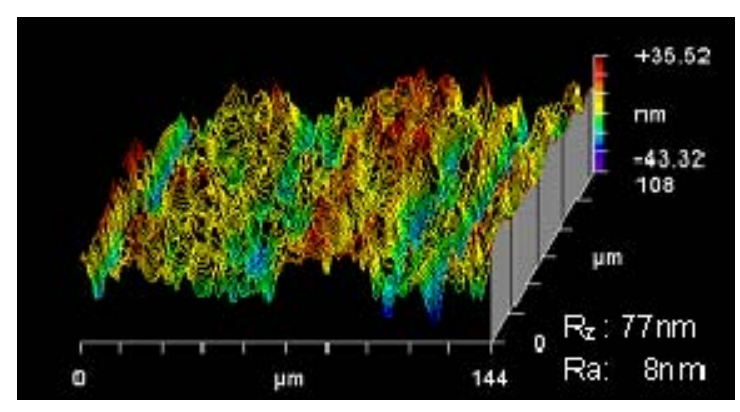

Fig. 8 Surface profile of a stainless steel specimen cut with the cBN tool under suitable conditions (i.e., without spark generation) during high-speed milling. $R_{z}$ was measured by a non-contact surface profilometer.

\subsection{Application to other materials}

Fig. 9 shows the microscopic surface images of ADC12 (a and b) and S50C specimens (c and d) cut with each tool at a cutting speed of $2 \mathrm{~m} / \mathrm{min}, \mathrm{f}=5 \mu \mathrm{m}$, and $\mathrm{a}_{\mathrm{p}}=$ $5 \mu \mathrm{m}$ under dry conditions with air blowing. For the ADC12 specimens, the surface created by the diamond tool exhibited a metallographic structure without polishing. In contrast, the surface created by the $\mathrm{cBN}$ tool on $\mathrm{ADC} 12$ resembled an abrasion surface. The $\mathrm{cBN}$ tool showed formation of build-up edge after cutting the ADC12 specimens. The attached ADC12 cutting chips on the blade edge made it difficult to create the mirror surface. For the S50C specimens, the surface created by the $\mathrm{cBN}$ tool was very similar to that observed for the stainless steel specimens. When the diamond tool was used on S50C, the surface had some scratched paths, though not to the extent of those 
seen on the surface of stainless steel that was cut with the diamond tool.
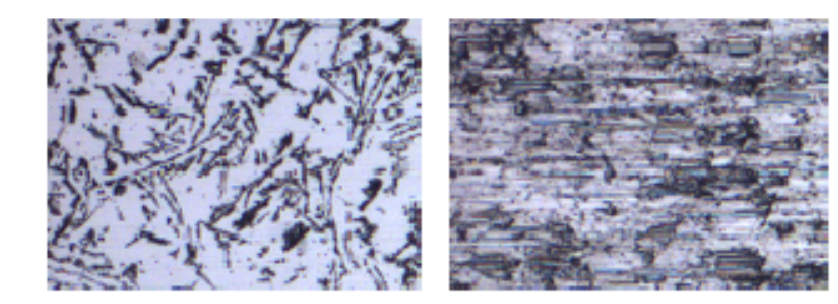

a) Diamond lool on ADCA2 b) cEN tool on ADC1 2
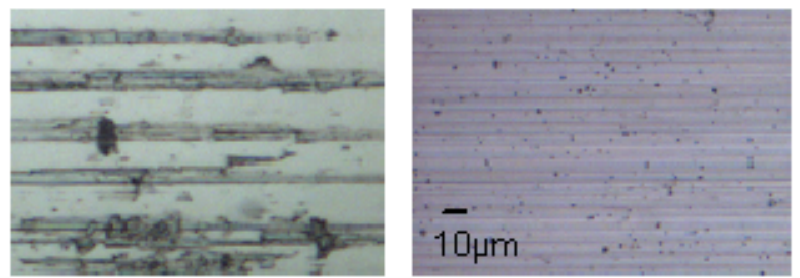

c) Diamond lool on SaOC di cEN tool on SaOC

Fig. 9 Microscopic surface images of ADC12 and S50C cut by both types of tools: a)

diamond tool on $\mathrm{ADC12}, \mathrm{b}$ ) $\mathrm{cBN}$ tool on $\mathrm{ADC} 12, \mathrm{c}$ ) diamond tool on $\mathrm{S} 50 \mathrm{C}$, and d) $\mathrm{cBN}$ tool on S50C: cutting speed $=2 \mathrm{~m} / \mathrm{min}, \mathrm{f}=5 \mu \mathrm{m}$, and $\mathrm{a}_{\mathrm{p}}=5 \mu \mathrm{m}$ under dry conditions.

\section{Discussion}

Ultra high precision machining is required for surface finishing in the mould manufacturing process. When the $\mathrm{cBN}$ tools were used, the best $R_{z}$ value obtained was $50 \mathrm{~nm}$, but this surface quality was not consistently achieved: $R_{Z}$ ranged widely between 50 and $100 \mathrm{~nm}$, even for surfaces cut under the same fly-cutting conditions. Although 
this result indicates that tool wear occurred during the surface machining process, this wear was only on the order of $100 \mathrm{~nm}$ or less (similar to the size of $\mathrm{cBN}$ particles) for a measured length of $144 \mu \mathrm{m}$ along the feed direction, including 72 lines of cutting path. The loss of particles at the cutting edge of the tool directly affects $R_{\mathrm{Z}}$ in precision cutting. However, the $\mathrm{cBN}$ tool was hard and retained enough of its particles to create surfaces with $R_{\mathrm{z}}<100 \mathrm{~nm}$. The precision cutting machine used in these experiments has been used to create copper surfaces with $R_{z}$ values as low as $30 \mathrm{~nm}$ with single-crystal diamond tools under fly-cutting in dry conditions (Furushiro et al., 2008). The best-quality steel surface obtained with the cBN tool in the present experiments had an $R_{z}$ close to this value $(<50 \mathrm{~nm})$. Ultra-precision cutting of ferrous materials might be attainable if this $\mathrm{cBN}$ tool was used in higher-precision machines. Importantly, in commercial mould manufacturing, finished surfaces could be attainable by this cBN tool cutting without grinding process.

Precision cutting tests were conducted in dry conditions with only air blowing in this experiment, and the $\mathrm{cBN}$ tools used herein created mirror-like surfaces on ferrous materials without the use of cutting oils. When cutting oils are used in precision machining, their subsequent elimination can cause physical damage to the machined surfaces. For the diamond tool cutting, white kerosene is sometimes used as a cutting oil 
because it is easy to clean with acetone. Since the cBN tool was used successfully in dry conditions, this tool could be useful for precision cutting of chemically reactive materials. Nevertheless, since tool life depends on blade wear caused by mechanical damages, heat generation, and chemical reactions between the tool and work material, an appropriate cutting oil that reduces these detrimental effects should be applied during cutting. For the cBN tools, $R_{z}$ values less than $100 \mathrm{~nm}$ were obtained for a blade lifetime of about 2 or $3 \mathrm{~km}$ for high-speed milling of stainless steels. This lifetime could be improved through the use of appropriate cutting oils.

Compared with the diamond tool, the $\mathrm{cBN}$ tool was much more useful for machining ferrous materials owing to its better resistance to tool wear caused by chemical reactions and heat generation. To obtain $R_{z}$ values less than $100 \mathrm{~nm}$ for ferrous materials without wear at the cutting edge of the diamond tool, the tool must be kept at a lower temperature, for instance, by supplying liquid nitrogen (Evans, 1991) or by using an ultrasonic vibration cutting system (Shamoto and Moriwaki, 1999). The fine-grain cBN tool apparently was resistant to high temperatures, because $R_{z}$ of the steel specimen was $\sim 100 \mathrm{~nm}$ even under the worst machining conditions, i.e., when sparks were generated in the high-speed milling tests. Recently, a cBN tool has been used for the machining of Ti alloys, which, like ferrous materials, are difficult to cut with diamond tools (Zoya and 
Krishnamurthy, 2000). The fine-grain cBN tool created herein therefore might be useful for the precision cutting of Ti alloys. However, when used in dry conditions, this cBN tool failed to produce a mirror-like surface on ADC12 specimens owing to the formation of $\mathrm{ADC} 12$ build-up on the blade edge. Although the surface of the $\mathrm{cBN}$ tool could be made as smooth as that of the single-crystal diamond tool at a level of $<100$ $\mathrm{nm}$, this smoothness was not adequate to avoid the adhesion of ADC12 cutting chips. For precision cutting under dry conditions, the polycrystalline $\mathrm{cBN}$ tool may therefore be unsuitable for adhesive materials such as $\mathrm{Al}$ and $\mathrm{Cu}$ alloys, even if the tool edge is made of ultra-fine particles. The generation of such build-up on the blade edge might be prevented by applying an appropriate cutting oil, because the cutting oil acts as a lubricant to remove cutting chips and to reduce the frictional heat generation that causes melting of the work material.

The tools made from sintered cBN chips can be re-polished and re-used, similar to other tools. Sintered cBN materials are more resistant to crack propagation than are single-crystal materials because polycrystalline materials are composed of numerous boundaries of small particles. Thus, the ultra-fine-grain cBN materials used here are not only reusable, but are also durable. 


\section{Conclusions}

A new cutting tool was developed from ultra-fine-grain $(<100 \mathrm{~nm})$, binderless cBN material fabricated by transforming hexagonal boron nitride ( $\mathrm{hBN}$ ) to $\mathrm{cBN}$ by means of sintering under an ultra-high pressure of $10 \mathrm{GPa}$ at $1800^{\circ} \mathrm{C}$. The surface roughness $\left(R_{z}\right)$ obtained at stainless steel surfaces subjected to planing with the cBN tool was approximately $100 \mathrm{~nm}$. High-precision surfaces, i.e., those with $R_{z}$ values $<100 \mathrm{~nm}$, were successfully obtained from high-speed milling with the cBN tool, and the results indicate that the newly developed $\mathrm{cBN}$ tool is useful for the ultra-precision or precision cutting of ferrous materials.

\section{References}

Bewilogua, K., Keunecke, M., Weigel, K., Wiemann, E., 2004. Growth and characterization of thick cBN coatings on silicon and tool substrates. Thin Solid Films 469-470, 86-91.

Brinksmeier, E., Gläbea, R. Osmer J., 2006. Ultra-precision diamond cutting of steel molds. Annals of the CIRP 55(1), 551-554. 
Evans, C., 1991. Cryogenic diamond turning of stainless steel, CIRP 40/1, 571-575.

Chou, Y. K., Evans, C. J., 1997. Tool wear mechanism in continuous cutting of hardened tool steels. Wear 212, 59-65.

Furushiro, N., Yokota, H., Fujisaki, K., Yamagata, Y., Kokubo, M., Himeno, R., Makinouchi, A., Higuchi, T., 2008. Development of three-dimensional internal information acquisition system based on consecutive precision machining. Journal of the JSPE (in Japanese) 74(6), 587-592.

Klocke, F., Demmer, A., Heselhaus, M., 2004. Material removal mechanisms in ultrasonic-assisted diamond turning of brittle materials. Int. J. Mater. Prod. Tech, 20(4), 231-238.

Luo, S. Y., Liao, Y. S., Tsai, T. Y., 1999. Wear characteristics in turning high hardness alloy steel by ceramic and CBN tools. J. Mater. Process. Technol. 88, 114-121.

Moriwaki, T., Shamoto, E., Song, Y. C., Kohda, S., Development of a elliptical vibration milling machine. Annals of the CIRP 53(1), 341-344.

Neo, K. S., Rahman, M., Li, X. P., Khoo, H. H., Sawa, M. Maeda, Y., 2003. Performance evaluation of pure CBN tools for machining of steel. J. Mater. Process. Technol. 140, 326-331.

Nishiguchi, T., Masuda, M., 1988. Precision cutting of ferreous metals with single 
crystal CBN cutting tools. Journal of the JSPE (in Japanese) 54(2), 384-389.

Paul, E., Evans, C. J., Mangamelli, A., McGlauflin, M. L., Polvani, R. S., 1996. Chemical aspects of tool wear in single point diamond turning. Precis. Eng. 18, 4-19. Shamoto, E., Moriwaki, T., 1994. Study on elliptical vibration cutting. Annals of CIRP 43(1), 35-38.

Shamoto, E., Moriwaki, T., 1999. Ultrasonic precision diamond cutting of hardened steel by applying ultrasonic elliptical vibration cutting. Annals of CIRP 48, 441-444.

Shimada, S., Tanaka, H., Higuchi, M., Yamaguchi, T., Honda, S., Obata, K., 2004. Thermo-chemical wear mechanism of diamond tool in machining of ferrous metals. Annals of the CIRP 53(1), 57-60.

Taniguchi, T., Akaishi, M., Kanke, Y., Yamaoka, S., 2004. TiC-diamond composite disk-heater cell assembly to generate temperature of $2000{ }^{\circ} \mathrm{C}$ in a large-volume belt-type high-pressure apparatus at 10GPa. Rev. Sci. Instrum. 75(6), 1959-1962.

Taniguchi, T., Akaishi, M., Yamaoka, S., 1999. Sintering of cubic boron nitride without additive at $7.7 \mathrm{GPa}$ and above $2000{ }^{\circ} \mathrm{C}$. J. Mater. Res. 14, 162-169.

Taniguchi, T., Yamaoka, S., 2001. Spontaneous nucleation of cubic boron nitride single crystal by temperature gradient method under high pressure. J. Cryst. Growth 222, $549-557$. 
Zoya, Z. A., Krishnamurthy, R., 2000. The performance of CBN tools in the machining of titanium alloys. J. Mater. Process. Technol. 100, 80-86. 